\section{ULTRASONOGRAPHY: the fifth anniversary of its global re-launch}

JEONG-SIK YU

Editor-in-Chief ULTRASONOGRAPHY

Time flies incredibly quickly, and 5 years have already passed since the worldwide re-launch of Ultrasonography. At this time, as we publish the first issue of the new 2019 volume, in my role as Editor-in-Chief, I would like to express my sincere appreciation for the efforts of all authors, reviewers, and editorial staff members, as well as the journal readers.

Ultrasonography has published 200 peer-reviewed articles during the last 5 years, and recently a total of 186,453 hits were recorded during a single month (October 2018) at the journal's homepage (https://www.e-ultrasonography.org/). After Ultrasonography was indexed in PubMed and SCOPUS, global submissions have increased. In 2014, during the first year after our re-launch, all authors of the 40 articles published were Korean. In contrast, in the last year, fully half of the 40 articles we published were written by international authors. The journal's unofficial 2017 impact factor was 2.838, as part of the core collection of the Web of Science via Emerging Sources Citation Index (ESCI), which corresponded to the 39th-highest of all 129 journals in the "Radiology, Nuclear Medicine \& Medical Imaging" subject category in Science Citation Index Expanded (SCIE), and the second-highest of all global academic peer-reviewed journals on medical ultrasound.

In 2018, the Korean Society of Ultrasound in Medicine (KSUM), the parent society of Ultrasonography, successfully hosted the annual conference of Asian Federation of Societies for Ultrasound in Medicine and Biology (AFSUMB). The significant contributions of East Asian researchers to medical imaging are well-known in academia, and as one of the leading global journals in the field of medical ultrasound, Ultrasonography will continue to play an indispensable role in covering recent advances and providing dedicated educational materials, in addition to publishing high-quality articles with valuable information for clinical practice.

ORCID: Jeong-Sik Yu: https://orcid.org/0000-0002-8171-5838

Jeong-Sik Yu, MD

Department of Radiology, Gangnam Severance Hospital, Yonsei University College of Medicine, 211 Eonju-ro, Gangnam-gu, Seoul 06273, Korea

Tel. +82-2-2019-3510, Fax.+82-2-3462-5472, E-mail: yjsrad97@yuhs.ac

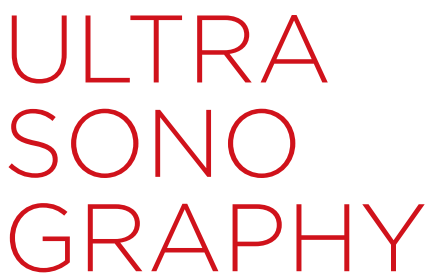

\section{EDITORIAL}

https://doi.org/10.14366/usg. 18073 pISSN: 2288-5919 • elSSN: 2288-5943 Ultrasonography 2019;38:1

Received: December 7, 2018

Revised: December 9, 2018

Accepted: December 10, 2018
This is an Open Access article distributed under the terms of the Creative Commons Attribution NonCommercial License (http://creativecommons.org/ licenses/by-nc/3.0/) which permits unrestricted noncommercial use, distribution, and reproduction in any medium, provided the original work is properly cited.

Copyright @ 2019 Korean Society of Ultrasound in Medicine (KSUM)

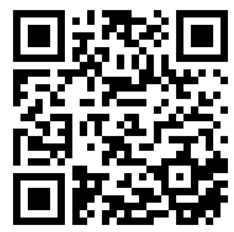

How to cite this article:

Yu JS. ULTRASONOGRAPHY: the fifth anniversary of its global re-launch. Ultrasonography. 2019 Jan;38(1):1. 